\title{
Single breath carbon monoxide transfer factor in different forms of chronic airflow obstruction in a general population sample
}

\author{
Ronald J Knudson, Walter T Kaltenborn, Benjamin Burrows
}

\begin{abstract}
The single breath transfer factor for carbon monoxide (TLCo), TLCo/alveolar volume (VA), and standard spirometric indices were measured in a survey of the randomly selected population sample of 1174 subjects enrolled in the Tucson epidemiological study of airways obstructive disease. Subjects were subdivided according to whether the $F E V_{1} \mid$ FVC ratio was under $65 \%, 65-75 \%$, or over $75 \%$. The influence of smoking on TLco was accounted for by expressing TLco as a percentage of the expected value-that is, of the value expected from the reported cigarette consumption. The 63 subjects who gave a history of physician confirmed asthma in reply to a questionnaire tended to have high values for TLCo, even when FEV $_{1} /$ FVC was reduced. In the absence of a given diagnosis of asthma, however, TLco and TLCo/VA were reduced when the $\mathrm{FEV}_{1}$ I FVC ratio was reduced, whether or not a clinical diagnosis of emphysema had been reported. This suggests that these subjects may have undiagnosed emphysema. This cross sectional analysis of our survey data suggests that subjects in our sample with spirometric evidence of chronic airflow obstruction have different forms of disease, characterised by different physiological features, in addition to the different risk factors and clinical courses reported earlier.
\end{abstract}

The general term chronic obstructive lung disease is commonly used to describe the condition characterised by persistent airflow obstruction. A primary objective of the Tucson epidemiological study of respiratory health ${ }^{1}$ has been to elucidate the nature of chronic airflow obstruction and the associated risk factors. It has become apparent that chronic obstructive lung disease is not a single disease in our population sample and that it may take more than one form. Subjects with asthma appear to develop a different form of disease than cigarette smokers without known asthma. The degree of ventilatory impairment may be similar in all forms of the disease, but the antecedent risk factors, course, and prognosis appear to differ. ${ }^{23}$ Subjects with airflow obstruction who report a diagnosis of "asthma" have been shown to share as risk factors atopy, eosinophilia, and a raised serum IgE level. In the absence of such a diagnosis of asthma these risk factors are not significant predictors of airflow obstruction. Subjects with an apparently asthmatic form of severe chronic airways obstruction also appear to have a much better prognosis than those with smoking related "chronic obstructive lung disease." The former appear to have a form of the disease that may be called chronic asthmatic bronchitis, to distinguish it from emphysematous forms of chronic obstructive lung disease.

To determine whether the results of the single breath carbon monoxide transfer factor (TLCO) test differ in subjects with chronic asthmatic bronchitis and in those with other forms of obstructive disease, we examined the results of this test in a randomly selected Tucson community population sample. We also sought to determine whether subjects with airflow obstruction but without a diagnosis of asthma have a low TLCO, consistent with emphysema.

\section{Methods}

All subjects had been enrolled in a random, stratified, cluster sample of the white nonMexican American population of Tucson, Arizona, which is being followed in a prospective epidemiological study of respiratory health. ${ }^{1}$ The single breath carbon monoxide transfer factor (TLCO) was measured during the seventh successive survey of the population, beginning in October 1981, and, to maximise participation, also during the following survey, which ended in May 1984. The surveys included standard spirometric testing ${ }^{4}$ and health information obtained from self administered questionnaires. In subjects who had had a recent acute respiratory problem (whether an asthma attack or an acute respiratory illness) at the time of interview, testing was postponed until the subject was back to what he or she regarded as "normal."

TLCo was measured with a Collins APEX DS/420 automated system. ${ }^{5}$ The testing guidelines were those mandated by the Epidemiology Standardisation Project. ${ }^{6}$ Previous analyses ${ }^{5}$ had shown that criteria for test acceptability could be broadened to include tests in which inspired volume is at least $85 \%$ of a separately determined vital capacity and that one acceptable test result could be used if duplicate results were not available. These broadened criteria maximised the number of results available for analysis without compromising quality. Tests yielded 
values for calculation of TLCO in units of $\mathrm{ml}$ CO $\min ^{-1} \mathrm{~mm} \mathrm{Hg}^{-1 \star}$ at STPD, alveolar volume (VA, derived from the single breath dilution of inspired helium), expressed in litres BTPS, and the specific transfer factor (TLCO/VA). From the spirometric tests performed at the same time the forced expiratory volume in the first second $\left(\mathrm{FEV}_{1}\right)$ and forced vital capacity (FVC) were obtained, the largest value from at least three FVC manoeuvres being selected.

Answers to the self administered questionnaire were used to identify population subgroups. Subjects were considered to have a diagnosis of "asthma," "emphysema," or "chronic bronchitis" if on the questionnaire they responded positively to the question of ever having had the disease and affirmed that a doctor had told them they had the condition. Subjects were categorised as "asymptomatic" if they denied having asthma, emphysema, chronic bronchitis, bronchiectasis, dyspnoea on exertion, or attacks of shortness of breath, wheeze, or chest tightness. They also had never had chest (heart or lung) surgery and denied having heart trouble or any neuromuscular, musculoskeletal, or cerebrovascular problem that might affect test performance. Test data from the asymptomatic subjects who also denied ever regularly smoking cigarettes were used to derive our published reference equations for TLCO, VA, and TLCO/ VA. ${ }^{5}$ On the basis of these equations in this analysis, percentages of predicted values (for example, TLCo \% pred) are used to take into account sex, age, and height, but not being a smoker or non-smoker.

In previous analyses the effects of cigarette smoking and of stopping smoking on TLCO were examined in asymptomatic subjects with normal ventilatory function who had smoked cigarettes. ${ }^{7}$ From that analysis the following regression equations were derived to yield a $\%$ predicted value for TLCO and TLCo/VA that would be expected after taking cumulative cigarette consumption and current smoking into consideration:

$$
\begin{gathered}
\text { Expected TLco \% pred }= \\
110 \cdot 660-4.812(\text { pack y })^{1 / 3}-9 \cdot 714^{\star} \\
\text { Expected TLco/VA } \% \text { pred }= \\
107.084-4.116(\text { pack } y)^{1 / 3}-7 \cdot 350^{\star}
\end{gathered}
$$

Cumulative cigarette consumption is expressed as the cube root of pack years of smoking; current smoking decrement, indicated by the asterisk, is subtracted only if the subject is a current smoker. Carbon monoxide back pres-

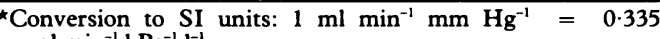
$\mathrm{mmol} \mathrm{min}{ }^{-1} \mathrm{kPa}^{-1} \mathrm{I}^{-1}$ sure or carboxyhaemoglobin were not measured in this survey, so TLCo in current smokers is likely to be systematically underestimated. This is taken into account, however, by the current smoking decrement in the above equation and thus in the calculation of the expected TLCO or TLCO/VA \% pred.

The percentage of the expected value was used in this analysis for TLCO and TLCO/VA to correct for smoking, it being assumed that a significant departure from $100 \%$ expected was a consequence of something other than smoking. This concept may be clarified by the following example. A current smoker whose expected TLCO was $80^{\circ}$ o pred would have a value $100 \%$ of that expected if his TLCO was indeed $80 \%$ pred. If, however, his TLCo was $60 \%$ pred it would be $75 \%$ of the expected value, the deficit resulting from a disease that may be caused by smoking but not merely from the fact that he smokes. For a nonsmoker the percentage of the expected value is equal to the percentage of the predicted value. This technique adjusts for different smoking habits among groups, but it tends to minimise the apparent decrement in TLCO that may occur in smoking related diseases.

We categorised subjects who failed to meet the questionnaire based criteria for being asymptomatic as "symptomatic," recognising that this is a non-specific category of people that includes smokers and non-smokers who may or may not have a specific respiratory disease.

Data were analysed on the University of Arizona CDC Cyber 175 computer system with programs from the Statistical Package for the Social Sciences (SPSS version 9.0). Analysis of variance and Duncan's multiple range test were used to test significance.

\section{Results}

Questionnaire information, spirometric values, and technically satisfactory measurements of TLco were obtained on 1174 subjects. Among the subjects who failed to meet the questionnaire based criteria for being free of symptoms or disease that might affect lung function, 17 had had surgical procedures affecting the chest wall or lung resection or had evidence of lung restriction $\left(\mathrm{FVC}<70 \%\right.$ pred and $\mathrm{FEV}_{1} / \mathrm{FVC}$ $>85 \%$ ). These were omitted from the analysis. Of the remaining 314 subjects who were categorised as symptomatic, seven said they had both "emphysema" and "asthma." They appeared to have a more severe form of

\begin{tabular}{|c|c|c|c|c|c|c|c|c|c|c|c|c|}
\hline \multirow{3}{*}{$\begin{array}{l}{ }_{o}^{o} F E V_{1} / F V C \\
>75 \\
65-75 \\
<65\end{array}$} & \multicolumn{4}{|l|}{$T L C O$} & \multicolumn{4}{|c|}{$T L C O / V_{A}$} & \multirow{2}{*}{\multicolumn{2}{|c|}{$\frac{F E V_{1}}{\% \text { predicted }}$}} & \multirow{2}{*}{\multicolumn{2}{|c|}{$\begin{array}{l}\text { Smokers } \\
\text { No }(\%)\end{array}$}} \\
\hline & \multicolumn{2}{|c|}{$o_{o}$ predicted } & \multicolumn{2}{|c|}{$\%$ expected } & \multicolumn{2}{|c|}{$\%$ predicted } & \multicolumn{2}{|c|}{$\%$ expected } & & & & \\
\hline & $\begin{array}{l}97 \cdot 65 \\
92 \cdot 19 \\
83 \cdot 39\end{array}$ & $\begin{array}{l}(15 \cdot 69) \\
(16 \cdot 71) \\
(22 \cdot 19)\end{array}$ & $\begin{array}{l}99 \cdot 86 \\
97 \cdot 14 \\
89 \cdot 96\end{array}$ & $\begin{array}{l}(15 \cdot 40) \\
(15 \cdot 93) \\
(22.31)\end{array}$ & $\begin{array}{l}97 \cdot 95 \\
92 \cdot 94 \\
82 \cdot 79\end{array}$ & $\begin{array}{l}(15 \cdot 12) \\
(17 \cdot 88) \\
(23 \cdot 89)\end{array}$ & $\begin{array}{r}100 \cdot 52 \\
98 \cdot 18 \\
88 \cdot 95\end{array}$ & $\begin{array}{l}(15 \cdot 06) \\
(17 \cdot 33) \\
(23 \cdot 28)\end{array}$ & $\begin{array}{r}108 \cdot 76 \\
94 \cdot 73 \\
73 \cdot 33\end{array}$ & $\begin{array}{l}(13.89) \\
(15.37) \\
(17.88)\end{array}$ & $\begin{array}{r}801 \\
263 \\
86\end{array}$ & $\begin{array}{l}(40.0) \\
(65.8) \\
(69 \cdot 8)\end{array}$ \\
\hline
\end{tabular}
disease but were too few for useful statistical analysis and were also excluded from the

Table 1 Influence of ventilatory function on mean (SD) carbon monoxide transfer factor (TLCO) values

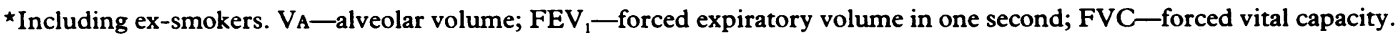


Figure 1 (a) Influence of "asthma" diagnosis on the percentage of the expected carbon monoxide transfer factor (TLCO) value in subjects categorised according to ${ }_{0} F E V$, forced vital capacity (FVC) ratio. Data from all subjects tested are shown. (b) Influence of "asthma" diagnosis on ${ }^{\circ}{ }_{0}$ expected TLCO in subjects categorised according to ${ }_{0}{ }_{0} F E V_{l} / F V C$ ratio. Only data from the 307 subjects classified as

"symptomatic" are shown.

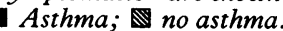
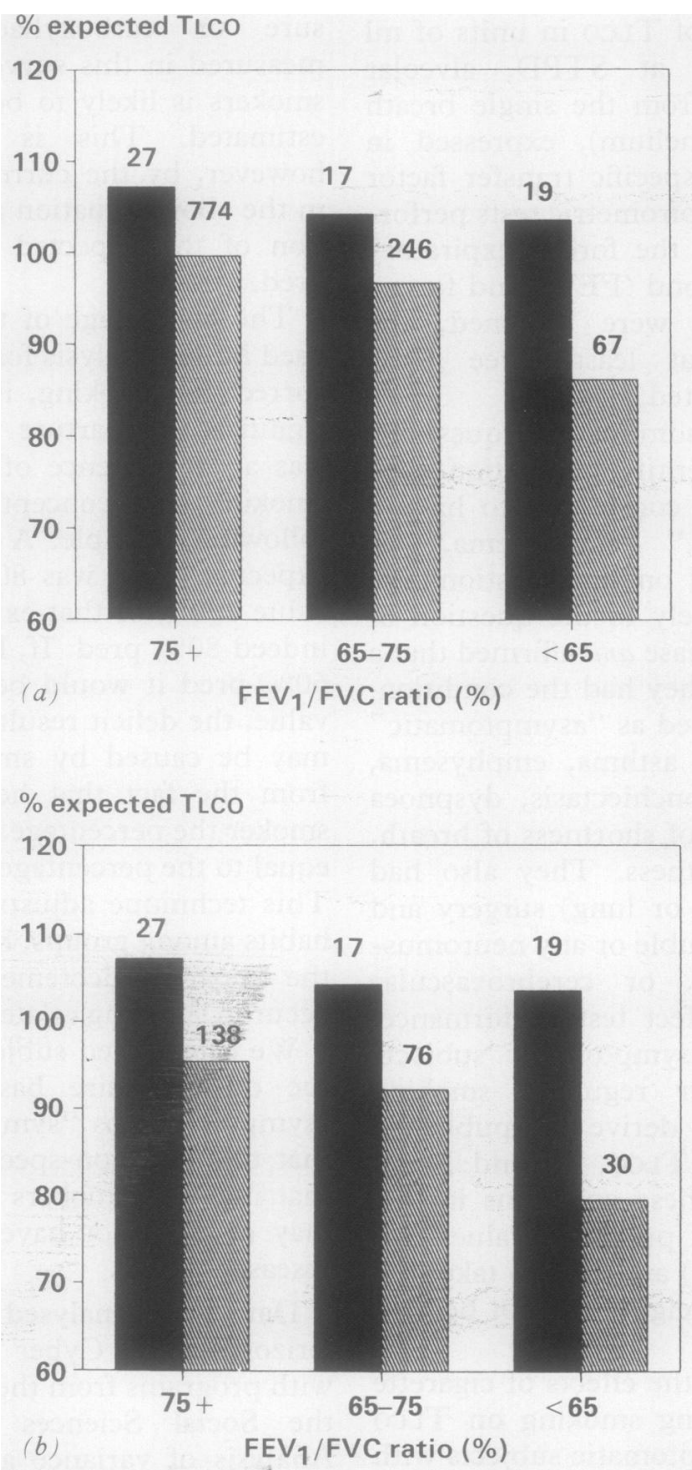

analysis. Data from the remaining population sample of 1150 subjects were examined for a relation between TLCO and spirometric variables, and the influence of diagnosis, symptoms, and smoking on these lung function variables.

Because Trco and Tlco/VA were clearly related to ventilatory function, we have classified the population by severity of airflow obstruction into three groups according to the $\mathrm{FEV}_{1} / \mathrm{FVC}$ ratio: $<65 \%, 65-75 \%$, and $>75 \%$. Mean TLCo and TLCo/VA, expressed as both $\%$ predicted $^{5}$ and $\%$ expected $^{7}$ (as defined above), for subjects subdivided by $\mathrm{FEV}_{1} / \mathrm{VC}$ ratio are shown in table 1 . The differences between the $\%$ predicted and \% expected values reflect the correction for smoking habit and exposure. In the subsequent analyses TLCO and TLCo/VA are expressed as $\%$ expected.

The 63 subjects who reported a diagnosis of "asthma" and the remainder of the population were again classified by $\mathrm{FEV}_{1} / \mathrm{FVC}$. The influence of a diagnosis of asthma on $\%$ expected TLCO are shown in figure $1 a$. Subjects with a diagnosis of asthma had significantly higher values for TLCO than those without such a diagnosis if the $\mathrm{FEV}_{1} / \mathrm{FVC}$ was $75 \%$ or more (p $=0.012)$ or under $65 \%(p=0.002)$; the difference failed to achieve significance in the $65-75 \%$ group $(p=0 \cdot 058)$. When analysis was confined to the 307 "symptomatic" subjects, (fig $1 b$ ) subjects with reported asthma had significantly higher $\%$ expected TLCO values ( $p$ $<0.01$ ) for all categories of $\mathrm{FEV}_{1} / \mathrm{FVC}$. The results were similar when TLCO/VA was used in the analyses shown in these and subsequent figures.

We examined further the influence of smoking by using the \% expected TLco to separate the independent effect of smoking from the effect related to a disease caused by smoking. Subjects with a diagnosis of asthma had well preserved expected TLCO whether or not they smoked. The differences in \% expected TLco between the 23 subjects with a diagnosis of asthma who had smoked and the $\mathbf{4 0}$ who had not smoked were not significant either for the total group or when they were grouped by $\mathrm{FEV}_{1} / \mathrm{FVC}$. Data from subjects with a diagnosis of asthma, regardless of smoking history, have therefore been compared with the data from non-asthmatic non-smokers and nonasthmatic smokers, data from the entire population sample being used (fig 2). The TLCo \% expected was greater in those with a diagnosis of asthma than in non-asthmatic nonsmokers $(p<0.05)$ and smokers $(p<0.01)$ and the value in non-asthmatic non-smokers was greater than in smokers $(p<0.01)$.

The same comparisons by $\mathrm{FEV}_{1} / \mathrm{FVC}$ subgroup are shown in figure 3 , which shows that far more subjects with an $\mathrm{FEV}_{1} / \mathrm{FVC}$ less than $75 \%$ had been smokers than non-smokers. The $\%$ expected TLCo was significantly greater in subjects given a diagnosis of asthma than in non-asthmatic smokers in all three categories of $\mathrm{FEV}_{1} / \mathrm{FVC}$. Although non-asthmatic nonsmokers tended to have higher values for $\%$ expected TLCo than smokers, the differences 


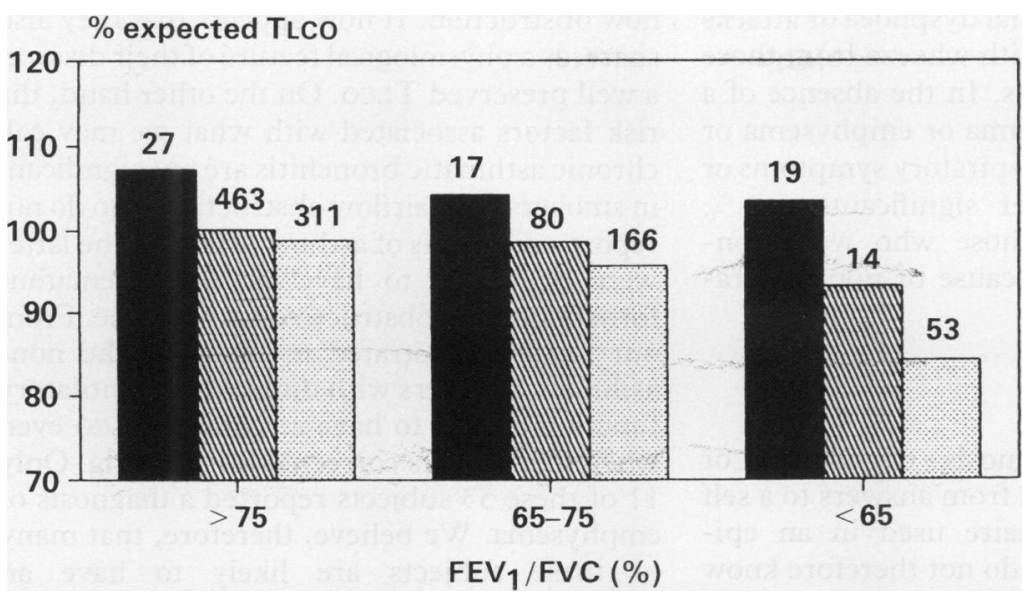

Figure 3 Carbon monoxide transfer factor (TLCO) expressed as percentage of expected value (corrected for smoking) in subjects with diagnosis of "asthma" (regardless of

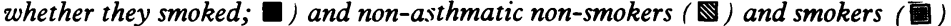
categorised according to ${ }^{\circ} F E V, \mid F V C$ ratio. Because values from smokers were not significantly different from those of non-smokers if there was a history of "asthma" results for "asthmatics" were combined. Data from all subjects tested are shown.

were not significant when subjects were divided into $\mathrm{FEV}_{1} / \mathrm{FVC}$ subgroups.

Because the lower \% expected Thco in smokers with diminished ventilatory function (fig 3) led us to suspect that these nonasthmatic subjects may include many with an emphysematous form of airflow obstruction, we examined the relation of respiratory symptoms and other diagnoses to \% expected TLCo (table 2). The population was again classified by $\mathrm{FEV}_{1} / \mathrm{FVC}$ and subjects were divided into the following subgroups: those with a questionnaire based diagnosis of asthma, those who reported a diagnosis of emphysema, those with other respiratory diagnoses or symptoms listed above, those with non-respiratory disorders that placed them in the symptomatic category, and those who met the criteria for being free of symptoms or disease and could be called asymptomatic. Subjects who were considered to be symptomatic because of a non-respiratory disorder included those with heart disease and cerebrovascular, neuromuscular, and musculoskeletal disorders.

When the 21 subjects who reported a diagnosis of "emphysema" were compared with the remainder of the population, they had the lowest values for TLCO $(p<0.01)$ and poorer ventilatory function than other subgroups. These subjects were distributed throughout all $\mathrm{FEV}_{1} / \mathrm{FVC}$ subgroups, however (table 2). Of the 53 smokers with an $\mathrm{FEV}_{1} / \mathrm{FVC}$ of less than $65 \%$, only 11 reported a diagnosis of "emphysema" and their mean \% expected TLCo did not differ from that of the remaining 42 (fig 3). Two subjects who reported a diagnosis of "emphysema" appeared among the 463 non-smokers with an $\mathrm{FEV}_{1} / \mathrm{FVC}$ of $75 \%$ or more and a well preserved TLCO.

Finally, we examined the relations between other diagnoses and respiratory symptoms and TLCo. Asymptomatic subjects, on average, had better lung function than those categorised as symptomatic. From answers to the self administered questionnaire $5.0 \%$ of the population of 1174 subjects tested had dyspnoea on exertion and $4.7 \%$ had attacks of shortness of breath with wheeze. Subjects with these complaints had significantly lower $\%$ expected TLCO than the remainder of the population. The $\%$ expected TLCO in the $5.3 \%$ of the population sample who indicated that they had "chronic bronchitis" did not, however, differ significantly from that of the remainder of the population.

When the analysis was confined to symptomatic subjects, a given diagnosis of asthma or emphysema or both distinguished separate subgroups. When subjects with these diagnoses were excluded from the symptomatic subjects, the \% expected TLCo did not distin-

Table 2 Carbon monoxide transfer factor (TLCO) by categories of ventilatory function and diagnoses and symptoms (mean (SD) values)

\begin{tabular}{|c|c|c|c|c|c|c|c|c|c|c|c|}
\hline \multirow[b]{2}{*}{$\begin{array}{l}\% \mathrm{FEV}_{1} / \mathrm{FVC}>75 \% \\
\text { Asthma } \\
\text { Emphysema } \\
\text { Other respiratory disorder } \\
\text { Non-respiratory disorder } \\
\text { Asymptomatic }\end{array}$} & \multicolumn{2}{|c|}{$\begin{array}{l}T L C O^{\star} \\
\% \text { expected }\end{array}$} & \multicolumn{2}{|c|}{$\begin{array}{l}T L C O / V A^{\star} \\
\% \text { expected }\end{array}$} & \multicolumn{2}{|c|}{$F E V, \%$ pred } & \multicolumn{2}{|c|}{ Age (y) } & \multirow{2}{*}{$\begin{array}{l}\% \text { male } \\
\\
29 \cdot 6 \\
25 \cdot 0 \\
37 \cdot 5 \\
35.9 \\
44 \cdot 8\end{array}$} & \multicolumn{2}{|c|}{$\begin{array}{l}\text { Smokers } \dagger \\
\text { No }(\%)\end{array}$} \\
\hline & $\begin{array}{r}107 \cdot 19 \\
80 \cdot 51 \\
97 \cdot 56 \\
94 \cdot 62 \\
100 \cdot 52\end{array}$ & $\begin{array}{l}(17 \cdot 46) \\
(19 \cdot 63) \\
(16 \cdot 69) \\
(16 \cdot 32) \\
(14 \cdot 81)\end{array}$ & $\begin{array}{r}107 \cdot 04 \\
93 \cdot 34 \\
100 \cdot 99 \\
98 \cdot 90 \\
100 \cdot 45\end{array}$ & $\begin{array}{l}(19 \cdot 51) \\
(20 \cdot 85) \\
(14 \cdot 71) \\
(15 \cdot 71) \\
(14 \cdot 74)\end{array}$ & $\begin{array}{r}108 \cdot 01 \\
98 \cdot 36 \\
102 \cdot 80 \\
105 \cdot 11 \\
109 \cdot 82\end{array}$ & $\begin{array}{l}(13 \cdot 19) \\
(21 \cdot 40) \\
(13 \cdot 68) \\
(14 \cdot 51) \\
(13 \cdot 62)\end{array}$ & $\begin{array}{l}37 \cdot 4 \\
67 \cdot 0 \\
52 \cdot 6 \\
59 \cdot 1 \\
38 \cdot 5\end{array}$ & $\begin{array}{r}(18 \cdot 7) \\
(7 \cdot 1) \\
(19 \cdot 6) \\
(19 \cdot 3) \\
(20 \cdot 0)\end{array}$ & & $\begin{array}{r}27 \\
4 \\
56 \\
78 \\
636\end{array}$ & $\begin{array}{l}(33 \cdot 3) \\
(50 \cdot 0) \\
(48 \cdot 2) \\
(50 \cdot 0) \\
(38 \cdot 2)\end{array}$ \\
\hline $\begin{array}{l}\% \mathrm{FEV}_{1} / \mathrm{FVC} 65-75 \% \\
\text { Asthma } \\
\text { Emphysema } \\
\text { Other respiratory disorder } \\
\text { Non-respiratory disorder } \\
\text { Asymptomatic }\end{array}$ & $\begin{array}{r}104 \cdot 24 \\
84 \cdot 63 \\
91 \cdot 08 \\
94 \cdot 21 \\
98 \cdot 64\end{array}$ & $\begin{array}{l}(14 \cdot 66) \\
(20 \cdot 40) \\
(16.92) \\
(13.24) \\
(15 \cdot 80)\end{array}$ & $\begin{array}{r}107 \cdot 58 \\
83 \cdot 24 \\
94 \cdot 26 \\
100 \cdot 22 \\
97 \cdot 97\end{array}$ & $\begin{array}{l}(15 \cdot 38) \\
(19 \cdot 06) \\
(19 \cdot 83) \\
(16 \cdot 85) \\
(16 \cdot 70)\end{array}$ & $\begin{array}{l}87 \cdot 82 \\
98 \cdot 58 \\
93 \cdot 64 \\
91 \cdot 60 \\
96 \cdot 21\end{array}$ & $\begin{array}{l}(10.88) \\
(16.90) \\
(19.37) \\
(19.00) \\
(13.75)\end{array}$ & $\begin{array}{l}42 \cdot 1 \\
72 \cdot 7 \\
62 \cdot 7 \\
68 \cdot 8 \\
55 \cdot 4\end{array}$ & $\begin{array}{r}(21 \cdot 7) \\
(9 \cdot 2) \\
(18 \cdot 3) \\
(13 \cdot 8) \\
(17 \cdot 2)\end{array}$ & $\begin{array}{l}29 \cdot 4 \\
50 \cdot 0 \\
50 \cdot 0 \\
42 \cdot 5 \\
50 \cdot 0\end{array}$ & $\begin{array}{r}17 \\
6 \\
30 \\
40 \\
170\end{array}$ & $\begin{array}{l}(41 \cdot 2) \\
(100) \\
(73 \cdot 3) \\
(62 \cdot 5) \\
(66 \cdot 5)\end{array}$ \\
\hline $\begin{array}{l}\% \mathrm{FEV}_{1} / \mathrm{FVC}<65 \% \\
\text { Asthma } \\
\text { Emphysema } \\
\text { Other respiratory disorder } \\
\text { Non-respiratory disorder } \\
\text { Asymptomatic }\end{array}$ & $\begin{array}{r}103 \cdot 51 \\
82 \cdot 56 \\
75 \cdot 10 \\
80 \cdot 56 \\
91 \cdot 51\end{array}$ & $\begin{array}{l}(17 \cdot 42) \\
(27 \cdot 33) \\
(20 \cdot 90) \\
(18 \cdot 24) \\
(20 \cdot 81)\end{array}$ & $\begin{array}{r}106 \cdot 06 \\
81 \cdot 97 \\
77 \cdot 72 \\
77 \cdot 04 \\
88 \cdot 18\end{array}$ & $\begin{array}{l}(17 \cdot 15) \\
(25 \cdot 72) \\
(27 \cdot 48) \\
(21 \cdot 68) \\
(20 \cdot 37)\end{array}$ & $\begin{array}{l}65 \cdot 75 \\
60 \cdot 44 \\
67 \cdot 35 \\
77 \cdot 82 \\
81 \cdot 59\end{array}$ & $\begin{array}{l}(15 \cdot 49) \\
(24 \cdot 83) \\
(16 \cdot 26) \\
(12 \cdot 32) \\
(14 \cdot 06)\end{array}$ & $\begin{array}{l}48 \cdot 8 \\
63 \cdot 5 \\
70 \cdot 0 \\
69 \cdot 3 \\
61 \cdot 8\end{array}$ & $\begin{array}{r}(19 \cdot 5) \\
(8 \cdot 6) \\
(7 \cdot 9) \\
(13 \cdot 1) \\
(13 \cdot 4)\end{array}$ & $\begin{array}{l}57 \cdot 9 \\
63 \cdot 6 \\
70 \cdot 0 \\
66 \cdot 7 \\
54 \cdot 1\end{array}$ & $\begin{array}{r}19 \\
11 \\
10 \\
9 \\
37\end{array}$ & $\begin{array}{r}(36.8) \\
(100.0) \\
(90.0) \\
(88.9) \\
(67.6)\end{array}$ \\
\hline
\end{tabular}

*The \% expected TLCO is significantly $(p<0.05)$ greater for the group with asthma than for each of the other groups in each category of $\%$ FEV $/ F V C$ with the exception of the asymptomatic group with $\% \mathrm{FEV}_{1} / \mathrm{FVC} 65-75 \%$. The \% expected transfer coefficient (TLCo/VA) is significantly greater for the asthma group than for each of the other groups in the $\% \mathrm{FEV}, / \mathrm{FVC}<65 \%$ category, significantly greater than for each of the other groups except non-respiratory disorder in the $\% \mathrm{FEV}_{1} / \mathrm{FVC} 65-75 \%$ category, and significantly greater than for the non-respiratory disorder group and the asymptomatic group in the $\%$ FEV $/$ FVC $>75 \%$ category. Duncan's multiple range test was used to test significance.

†Including ex-smokers. 
guish those with exertional dyspnoea or attacks of shortness of breath with wheeze from those without these complaints. In the absence of a specific diagnosis of asthma or emphysema or both, those with other respiratory symptoms or diagnoses did not differ significantly in \% expected TLCo from those who were considered symptomatic because of non-respiratory disease (table 2 ).

\section{Discussion}

In this study a diagnosis of asthma or emphysema was derived from answers to a self administered questionnaire used in an epidemiological study. We do not therefore know the basis for the diagnosis in each case. If we assume that diminished ventilatory function and low TLCO are characteristic of emphysema, clearly not all of those who reported this diagnosis fit such a picture. We therefore question the reliability of this diagnostic label. A reported diagnosis of "chronic bronchitis" alone did not appear to distinguish a characteristic subgroup, which is consistent with the observations of Burrows and associates. ${ }^{2} \mathrm{Al}-$ though reported symptoms of attacks of shortness of breath with wheeze, as expected, were common among subjects with a diagnosis of asthma, such symptoms in the absence of a diagnosis of asthma did not show the same relation to TLCO that was seen in those with such a diagnosis. A reported diagnosis of asthma, alone or in combination with a diagnosis of chronic bronchitis, appeared to distinguish a subgroup with remarkably well preserved Tico. On the basis of the mean $\%$ expected value, TLCO in subjects with a diagnosis of asthma was well preserved and over $100^{\circ}$ of the expected value even if they smoked. Among subjects who had not been given a diagnosis of asthma, however, smokers had a significantly lower Tico than nonsmokers, even when TLCO was expressed as a percentage of the predicted TLCo that would be expected in view of their smoking. This suggests that non-asthmatic smokers may be affected by a disease related to smoking. Far more non-asthmatic subjects with diminished ventilatory function were smokers than nonsmokers, as shown in figure 3. Smoking appears in these subjects to explain both the lower TLCO and the decreased ventilatory function. In contrast, subjects with a history of asthma who had a low $\mathrm{FEV}_{1} / \mathrm{FVC}$ had very well preserved TLCo.

If we accept an $\mathrm{FEV}_{1} / \mathrm{FVC}$ ratio below $65 \%$ as indicating chronic obstructive pulmonary disease, our results show that subjects with this level of ventilatory dysfunction who have been given a diagnosis of asthma have significantly higher values for TLCO and TLCO/VA than subjects without such a history. Earlier analyses of data from our population study ${ }^{23}$ have shown that subjects with chronic airflow obstruction who report a diagnosis of asthma form a distinct group who share the risk factors of atopy, eosinophilia, and raised serum IgE levels, with apparently a more benign course of disease than non-asthmatic smokers with air- flow obstruction. It now appears that they also share, as a physiological feature of their disease, a well preserved TLCO. On the other hand, the risk factors associated with what we may call chronic asthmatic bronchitis are not significant in smokers with airflow obstruction who do not report a diagnosis of asthma. Many of the latter were presumed to have an emphysematous form of chronic obstructive lung disease. From our results, illustrated in figure 3 , the nonasthmatic smokers with diminished ventilatory function appear to have a reduced TLco even when this value is corrected for smoking. Only 11 of these 53 subjects reported a diagnosis of emphysema. We believe, therefore, that many of these subjects are likely to have an emphysematous form of airflow obstruction that has not yet received a diagnostic label.

In our subjects with a diagnosis of asthma the TLCo and TLCo/VA were not only well preserved but, as shown in the tables and figures, above $100 \%$ of the expected values and higher than in any other group, including the asymptomatic subjects $(p<0.01)$. This observation, based on our randomly selected community population sample, is consistent with previous data obtained from patients in clinical or hospital based studies. ${ }^{8-11}$ In these studies an increase in TLCO in asthma appeared to be associated with airflow obstruction and was observed to decrease with relief of obstruction by aerosol bronchodilator. ${ }^{12} 13$ The physiological changes underlying this association have been investigated. Keens and coworkers $^{9}$ found an increase in single breath TLCo in normal subjects when the test was carried out with an inspiratory obstruction in the circuit. They suggested that the more negative intrathoracic pressure during inspiration associated with the airway obstruction increased pulmonary capillary blood volume (VC). Stewart ${ }^{11}$ measured pulmonary capillary blood volume in healthy subjects and asthmatic patients with mild airflow obstruction and found $T_{L C O}$ and VC/VA to be higher in the asthmatic group and to increase with increasing airflow obstruction. These observations may explain the increase in TLCO associated with asthma that we and others have observed.

In summary, subjects in our population sample who show chronic airflow obstruction appear to have different forms of disease, characterised by different physiological features, as well as different risk factors and clinical courses. The single breath carbon monoxide transfer factor was well preserved or raised in subjects given a diagnosis of asthma even when ventilatory function was impaired. On the other hand, most subjects with chronic airflow obstruction and reduced TLCo were cigarette smokers without a diagnosis of asthma. They are likely to include many with an emphysematous form of disease.

We would like to express appreciation to Warren E Collins Inc for providing the equipment used in this study and gratefully to acknowledge the assistance of B Boyer and the Arizona SCOR epidemiological field staff for data gathering, and A Reeves in preparing the manuscript, and of the hundreds of citizens of Tucson, Arizona, whose willing cooperation made the study possible. 
1 Lebowitz MD, Knudson RJ, Burrows B. Tucson epidemiological study of obstructive lung diseases. I. Methodology and prevalence of disease. Am J Epidemiol 1975;102:137.

2 Burrows B, Bloom JW, Traver GA, Cline MG. The course and prognosis of different forms of chronic airways obstruction in a sample from the general population. $N$ Engl J Med 1987;317:1309-14.

3 Burrows B, Knudson RJ, Cline MG, Lebowitz MD. A reexamination of risk factors for ventilatory impairment. $\mathrm{Am}$ Rev Respir Dis 1988;138:829-36.

4 Knudson RJ, Lebowitz MD, Holberg CJ, Burrows B. Changes in the normal maximal expiratory flow-volume curve with growth and aging. Am Rev Respir Dis 1983; 127:725-34.

5 Knudson RJ, Kaltenborn WT, Knudson DE, Burrows B. The single breath carbon monoxide diffusing capacity: Reference equations derived from a healthy non-smoking population and effects of hematocrit. Am Rev Respir Dis population and effects of hematocrit. Am Rev Respir Dis

6 Ferris BG (ed) Rev Respir Dis 1978;118(Part 2):62-72.

7 Knudson RJ, Kaltenborn WT, Burrows B. The effects of cigarette smoking and smoking cessation on the carbon monoxide diffusing capacity of the lung in asymptomatic subjects. Am Rev Respir Dis 1989;140:645-51.

8 Evans CC, Ogilvie CM. Transfer factor in asthma. Lancet 1970;i:891.

9 Keens TG, Mansell A, Krastins IRB, et al. Evaluation of the single-breath diffusing capacity in asthma and cystic fibrosis. Chest 1979;76:41-4.

10 Pecora LJ, Bernstein IL, Feldman DP. Pulmonary diffusing capacity, membrane diffusing capacity, and capillary blood volume in children with intractable asthma with and without chronic overinflation of the lungs. J Allergy 1966; 37:204-15.

11 Stewart RI. Carbon monoxide diffusing capacity in asthmatic patients with mild airflow limitation. Chest 1988; 94:332-6.

12 Knudson RJ, Constantine HP. An effect of isoproterenol on ventilation-perfusion in asthmatic vs. normal subjects. $J$ Appl Physiol 1967;22:402-6.

13 Gazioglu K, Condemi JJ, Hyde RW, Kaltreider NL. Effect of isoproterenol on gas exchange during air and oxygen breathing in patients with asthma. Am J Med 1971;50: $185-90$. 